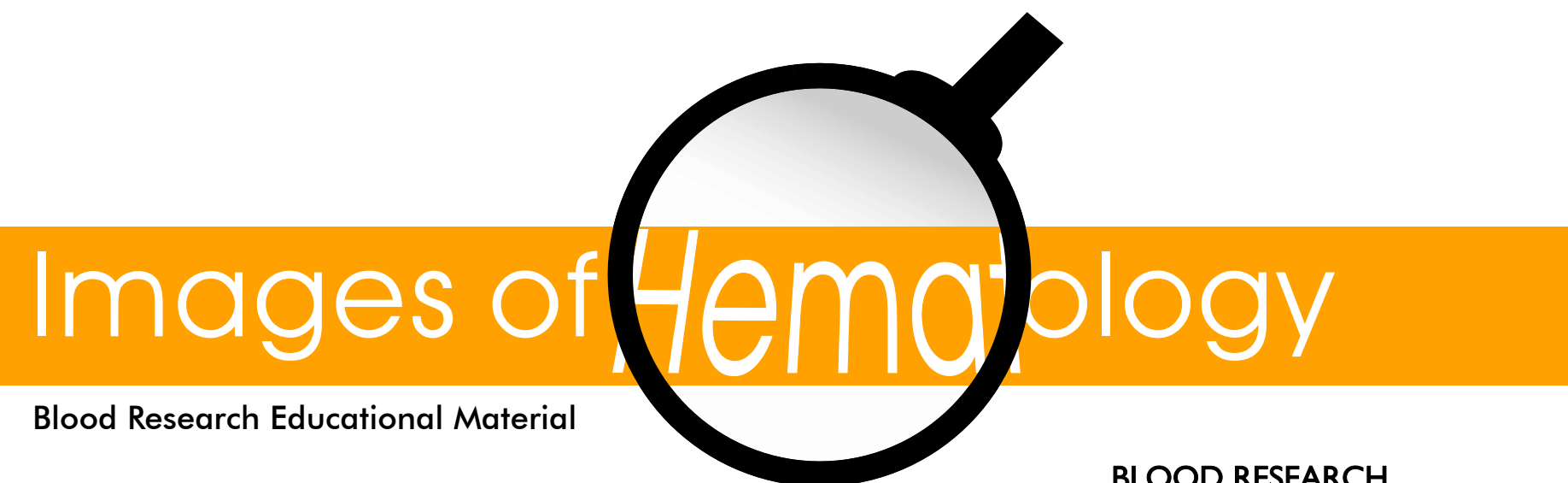

Volume $56 \cdot$ Number $1 \cdot$ March 2021

https://doi.org/10.5045/br.2021.2020269

\title{
Circulating megakaryocyte in primary myelofibrosis: an uncommon finding in a myelofibrosis blood smear
}

\author{
Pedro Asensi Cantó, María Leonor Senent Peris, Elvira Mora Casterá \\ Department of Haematology, Hospital La Fe, Valencia, Spain
}

Received on October 28, 2020; Revised on November 22, 2020; Accepted on January 19, 2021

Correspondence to Pedro Asensi Cantó, M.D., Department of Hematology, Hospital La Fe, Av. De Fernando Abril Martorell, Valencia 106-46026, Spain, E-mail: asensi_ped@gva.es
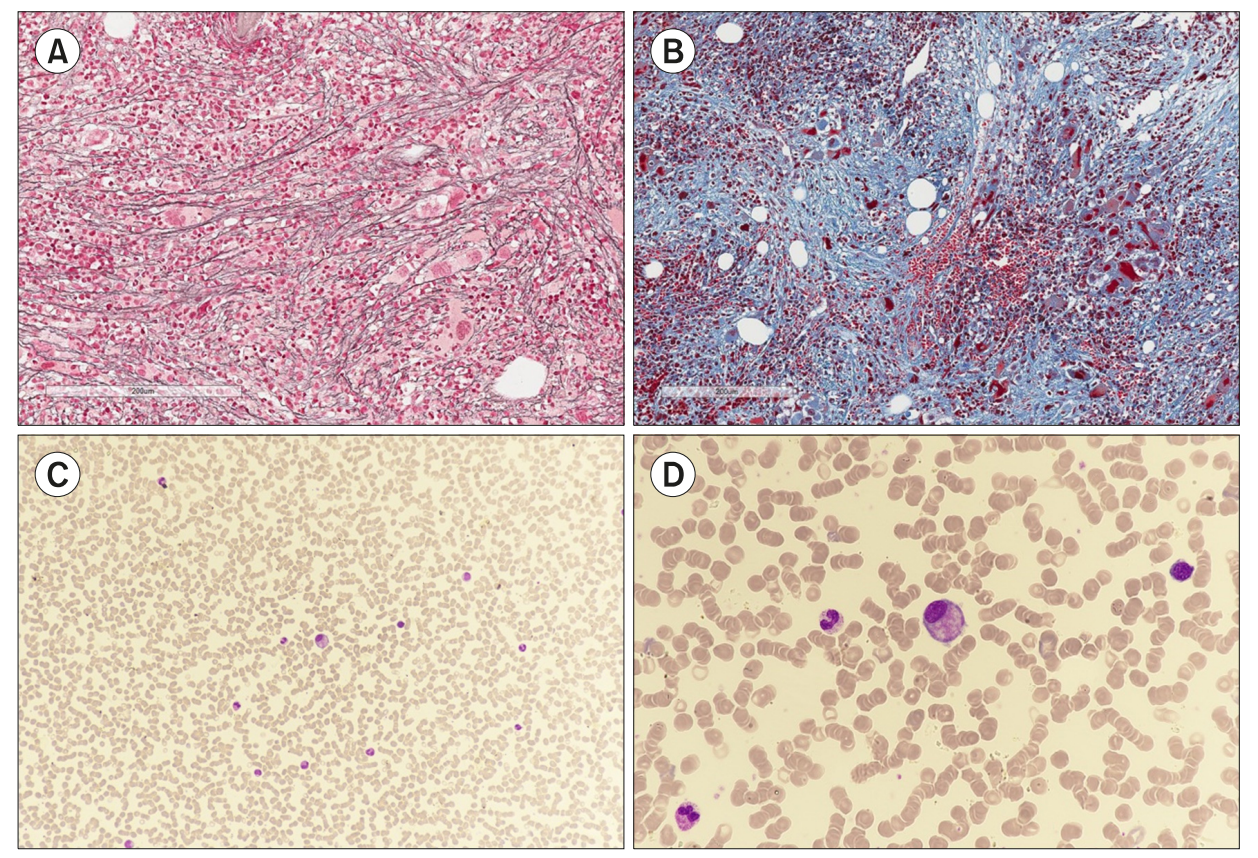

A 57-year-old man diagnosed with JAK2+ prefibrotic/early primary myelofibrosis (MF) progressed during the one-year follow-up to the overt fibrotic stage (A, reticulin stain, $\times 100$ and $\mathrm{B}$, Masson's trichrome stain, $\times 100$ ). Complete blood count showed no cytopenia (hemoglobin $14.4 \mathrm{~g} / \mathrm{dL}, 12.79 \times 10^{9}$ leukocytes/L, and $148 \times 10^{9}$ platelets/L). Initial blood-smear examination with low amplification objectives (C, Giemsa stain, $\times 200)$ showed the leukoerythroblastic morphology frequently seen in MF, with circulating myeloid precursors, erythroblasts, and anisopoikilocytosis. Surprisingly, a megakaryocyte was found in the body of the slide. Higher amplification (D, Giemsa stain, $\times 600$ ) enabled better characterization of this atypical small megakaryocyte with a non-lobated nucleus. Isolated (bare or naked) megakaryocyte nuclei are typical findings in MF. Intact megakaryocytes have rarely been reported in peripheral blood smears. If present, the feathered edge of the smear is the predilected location of these cells as they are among the largest cells in the sample and tend to be dragged when extending the sample, whereby their morphology may be altered. This finding emphasizes the importance of a systemic approach to blood-smear examination, starting scanning at low magnification for full coverage of the sample and identification of the best regions for higher magnification. 